\title{
Contemporaneidade e sofrimento psíquico: Relações entre modos de vida e demandas psicoterapêuticas
}

\author{
Contemporaneity and psychic suffering: Relationships between lifestyle and \\ psychotherapeutic requests
}

\author{
Ariane Patricia Ewald ${ }^{[a]}$, Michelle Thieme de Carvalho Moura ${ }^{[b]}$, Samira Meletti da Silva Goulart ${ }^{[c]}$
}

\footnotetext{
${ }^{[a]}$ Psicóloga, professora adjunta da UERJ, Programa de PósGraduação em Psicologia Social. Rio de Janeiro, RJ - Brasil, e-mail:arianeuerj@yahoo.com.br

${ }^{[b]}$ Psicóloga, mestranda em Psicologia Social pelo Programa de Pós-Graduação em Psicologia Social da UERJ, Rio de Janeiro, RJ - Brasil. E-mail: michelle_ thieme@yahoo.com.br

[c] Psicóloga, especialista em Psicologia Médica e Psicossomática pela Faculdade de Ciências Médicas da UERJ, Rio de Janeiro, RJ - Brasil, e-mail: samira.goulart@ig.com.br
}

Recebido: 27/11/2010 Received: $11 / 27 / 2010$

Aprovado: 30/03/2011 Approved: 03/30/2011

\section{Resumo}

Este artigo é desdobramento de trabalho realizado no Serviço de Psicologia da Universidade do Estado do Rio de Janeiro, durante o qual foram pesquisados 327 relatórios de triagens realizadas no serviço, com o objetivo de compreender o contexto social das demandas por psicoterapia e como estas sofrem influência de tal contexto. Por meio de uma análise quantitativa, foi observado que a principal queixa era referente à dificuldade de se relacionar com os outros, seguida por depressão, pânico e medos, e ansiedade. Em análise qualitativa, os resultados evidenciaram estreita relação entre as demandas por psicoterapia e o cenário atual, marcado pela "fluidez", pelo excesso, "urgência", desempenho e técnica, que geram insegurança e medos diversos, notadamente expressos nas queixas clínicas. Esses dados apontam para a importância de entender a queixa clínica dentro de um contexto histórico-social, fazendo-nos refletir sobre os modos de vida na atualidade.

Palavras-chave: Contemporaneidade. Psicoterapia. Psicologia social. Sofrimento psíquico.

\begin{abstract}
The present article is the result from a work developed at the Psychology Service of Universidade do Estado do Rio de Janeiro, where 327 screening reports in this service were researched, with the aim of understanding the social context of the requests for psychotherapy and how they are influenced by such context. By means of a quantitative analysis, it was noticed that the main complaint was on the difficulty in dealing with others, accompanied by depression, panic and fears, and anxiety. In a qualitative analysis, the results showed a close relationship between the request for psychotherapy and the present scenario, marked by "fluidity", excess, "urgency", performance and technique, which generate insecurity and different fears, remarkably expressed in clinical complaints. These data point to the importance of understanding the clinical complaints within a social and historical context, what leads us to reflect on the current ways of life.
\end{abstract}

Keywords: Contemporaneity. Psychotherapy. Social psychology. Psychological suffering. 


\section{Introduç̃̃o}

O problema da relação com os outros, a constatação do vazio existencial, da solidão e a ênfase social na busca por uma vida de sucesso e produtiva, parecem terem se tornado marcas da subjetividade moderna e passaram a estar cada vez mais presentes no rol das queixas nos consultórios terapêuticos. Tudo isso também parece estar aliado às crescentes dificuldades de estabelecer relacionamentos duradouros e amorosamente verdadeiros, espaço no qual a questão da intersubjetividade passou a ter uma dimensão problemática cada vez mais marcante. De forma cada vez mais acentuada, parecemos buscar soluções para nossos problemas existenciais e nosso sofrimento psíquico pelo menos de duas maneiras: primeiro pela mais avançada tecnologia, aqui incluído o arsenal psicofarmacológico; em seguida, pelos mais variados tipos de terapia, incluindo aí aquelas frutos de pesquisas acadêmicas, bem como aquelas que surgem, também, por modismos e misticismos de todo gênero.

Procurando compreender melhor esse contexto, realizamos uma pequena investigação no Serviço de Psicologia Aplicada da Universidade do Estado do Rio de Janeiro (SPA/UERJ), tendo como principal objetivo compreender de que forma a conjuntura social contemporânea vem contribuindo para os tipos de queixa que são destinadas ao Serviço de Psicologia. Tal estudo fazia parte do projeto de pesquisa Fazer uma psicoterapia: por quê? para quê? Sentido e representações da demanda endereçada aos profissionais psi, ligada ao Programa de Pós-Graduação em Psicologia Social da UERJ. A motivação para tal estudo iniciou-se a partir das discussões no grupo de estudos semanal, que fazia parte das supervisões de estágio em psicoterapia, a respeito dos atendimentos psicoterápicos realizados pelos estudantes de psicologia no SPA da UERJ.

Nestes encontros semanais, sempre motivadas pelos atendimentos e pela bibliografia que líamos e discutíamos, percebemos que as informações sobre as queixas se repetiam em diferentes atendimentos, revelando que as demandas se assemelhavam sob diversos aspectos, especialmente no que diz respeito ao modo de vida na atualidade. Assim, a partir dessa observação e do objetivo traçado, essas demandas foram analisadas mais minuciosamente por meio de uma pesquisa com levantamento de dados realizada nos relatórios de triagens efetuadas pelo serviço.

\section{Metodologia}

Nossa opção foi fazer o levantamento das triagens realizadas no SPA/UERJ, já que, ao fazer a inscrição para um trabalho terapêutico, cada cliente é encaminhado para uma sessão de triagem feita por estagiários, cujo relato por escrito permanece acessível aos estagiários e professores para um possível atendimento. Basicamente, o relato de triagem para nossa pesquisa deveria conter, de forma sintética, informações relevantes sobre o que levou o cliente a buscar o serviço de atendimento psicológico (o que poderíamos chamar de queixa). Informações como o sexo, a idade, a escolaridade e a profissão também fazem parte dessa ficha de triagem e, apesar de tais informações nos darem um panorama mais detalhado sobre os clientes, tais dados não são relevantes para o objetivo da discussão levantada aqui neste artigo. Os nomes dos clientes foram desconsiderados, já que para cada um havia um número de inscrição no serviço. Nesse sentido, não houve a necessidade de encaminhar o projeto para análise na Comissão de Ética, já que não haveria nenhum tipo de entrevista e que todas as informações dos clientes estariam completamente preservadas.

Nossa outra opção foi determinar o período sobre o qual faríamos o levantamento. Como estávamos em 2006, optamos por fazer o levantamento dos últimos dois anos, incluindo o ano em curso, já que o semestre estava adiantado e o momento das entrevistas de triagens já havia acontecido no serviço. Esse levantamento de dados foi feito durante todo o ano de 2006 e parte de 2007, já que para coletar os dados, os estagiários deveriam ler cada um dos relatos de triagens, num total de 327. Acreditamos, assim, que essa discussão e esses dados possam vir a ampliar nossas reflexões sobre nosso modo de vida na contemporaneidade e a própria demanda em psicoterapia.

Foram investigados os relatórios de triagem partindo do ano de 2004 até o primeiro semestre de 2006, totalizando 327 clientes com triagens disponíveis ao atendimento individual. Cabe salientar que o Serviço recebe ainda demandas para outros tipos de atendimento, mas a pesquisa centrava-se na demanda por psicoterapia individual. As 327 triagens disponíveis foram catalogadas em uma tabela na qual registramos o número e o ano de inscrição, a idade, o sexo, a escolaridade, profissão e a queixa principal de cada cliente. Já no caso de 
crianças, eram verificadas as queixas trazidas pela mãe ou responsável. Nosso objetivo final era verificar quais eram as demandas que chegavam ao serviço e como estas estariam relacionadas com os modos de vida contemporâneos.

\section{Resultados}

Após o levantamento desses dados, passamos a sua análise quantitativa, sendo necessária a distribuição das queixas em categorias. Para isso, nos detivemos fielmente às triagens, procurando considerar os termos registrados pelos estagiários nos relatórios, organizando-os por semelhança numa mesma categoria. As categorias encontradas foram: agitação; agressividade/comportamento explosivo; ansiedade; ciúmes; dedicação aos outros; depressão; dificuldade de relação com os outros; dificuldade de tomar decisões; dificuldade sexual; distúrbios alimentares; infantilidade; irritabilidade; luto; oscilação emocional; pânico e medos; pressão social; problema com a autoimagem; problema de atenção/dificuldade de aprendizagem; problema neurológico; problemas físicos/dor; problemas psíquicos/crise nervosa; psicossomática; sofreu agressão; TOC/compulsão; outras. Cada uma dessas categorias estão definidas na Quadro 1 a seguir:

\section{Quadro 1 - Definição de categorias a partir das queixas relatadas}

\begin{tabular}{|c|c|}
\hline Categorias formadas & Principais queixas \\
\hline Agitação & $\begin{array}{l}\text { Relatos de mudança de comportamento, com percepção de uma agitação motora, psíquica } \\
\text { e/ou emocional que de alguma forma prejudicou a qualidade de vida. Foram aqui agrupa- } \\
\text { das todas as queixas que apresentavam a palavra "agitação". }\end{array}$ \\
\hline $\begin{array}{l}\text { Agressividade/ comportamento } \\
\text { explosivo }\end{array}$ & $\begin{array}{l}\text { Relatos de procura por terapia após percepção de maior agressividade ou comportamento } \\
\text { agressivo com os outros, até mesmo situação de agressão física real. Foram aqui agru- } \\
\text { pados todos os relatos que traziam as palavras "agressividade" e/ ou "comportamento } \\
\text { explosivo". }\end{array}$ \\
\hline Ansiedade & $\begin{array}{l}\text { Queixas de maior agitação, acompanhadas de sensações de angustia e preocupações, que } \\
\text { referiam sempre a palavra "ansiedade" em seus relatos. }\end{array}$ \\
\hline Ciúmes & $\begin{array}{l}\text { Queixa principal para buscar terapia era o ciúme exagerado que sentia por algum } \\
\text { ente querido. Foram considerados os relatos que traziam a palavra "ciúmes" como } \\
\text { queixa principal. }\end{array}$ \\
\hline Dedicação aos outros & $\begin{array}{l}\text { Queixa de que a dedicação que tem às outras pessoas é o que dificulta sua vida e traz } \\
\text { problemas a ponto de sentir necessidade de buscar ajuda profissional. Em geral relatam } \\
\text { também uma negação de seu próprio cuidado em função do cuidado e atenção que sentem } \\
\text { necessidade de dar ao outro. Foram considerados os relatos que traziam as palavras "difi- } \\
\text { culdade de se relacionar com os outros". }\end{array}$ \\
\hline Depressão & Queixas de tristeza, choro, desânimo, que traziam a palavra "depressão" nos relatos. \\
\hline Dificuldade de relação com os outros & $\begin{array}{l}\text { Queixas de dificuldade de se relacionar com as outras pessoas em geral, sejam familiares } \\
\text { ou não; dificuldade de convívio social, solidão e isolamento. Foram considerados os relatos } \\
\text { que traziam as palavras "dificuldade de se relacionar com os outros" nas triagens. }\end{array}$ \\
\hline Dificuldade de tomar decisões & $\begin{array}{l}\text { Queixas de dificuldade de fazer escolhas, de saber o que se quer fazer na vida, seja em } \\
\text { relação à vida profissional ou pessoal (casamento, estudo, mudança de moradia, entre ou- } \\
\text { tros). Foram considerados os relatos que apresentavam as palavras "dificuldade de tomar } \\
\text { decisões" nas triagens investigadas. }\end{array}$ \\
\hline Dificuldade sexual & $\begin{array}{l}\text { Queixas de ejaculação precoce, dificuldades de ereção, problemas com relacionamento por } \\
\text { causa de alguma questão sexual. Foram considerados os relatos de triagens que possuíam } \\
\text { a expressão "dificuldade sexual" como queixa principal. }\end{array}$ \\
\hline
\end{tabular}


Quadro 1 - Definição de categorias a partir das queixas relatadas

(Conclusão)

\begin{tabular}{|c|c|}
\hline Categorias formadas & Principais queixas \\
\hline Distúrbios alimentares & $\begin{array}{l}\text { Queixas de problemas com a comida, anorexia, bulimia, dificuldade de comer por algum } \\
\text { outro motivo, compulsão por comer. Foram considerados os relatos que traziam a expres- } \\
\text { são "distúrbio alimentar" nas triagens. }\end{array}$ \\
\hline Infantilidade & $\begin{array}{l}\text { Queixas de comportamento infantil, inadequado a idade de desenvolvimento psíquico da pessoa, } \\
\text { sendo considerados os relatos que destacavam a palavra "infantilidade" como principal problema. }\end{array}$ \\
\hline Irritabilidade & $\begin{array}{l}\text { Queixas de instabilidade emocional, com humor irritadiço, não necessariamente com } \\
\text { desdobramentos no comportamento. Foram considerados os relatos que traziam a palavra } \\
\text { "irritabilidade" como principal queixa nas triagens. }\end{array}$ \\
\hline Luto & $\begin{array}{l}\text { Relatos de que o principal motivo para buscar psicoterapia foi o fato de ter morrido algum } \\
\text { membro da família ou pessoa próxima, com dificuldades de elaboração dessa perda. Consi- } \\
\text { deraram-se as triagens que traziam a palavra "luto" e/ ou "morte", como principal queixa. }\end{array}$ \\
\hline Oscilação emocional & $\begin{array}{l}\text { Queixas de mudanças de humor, decorrentes de variação do estado emocional, alternando } \\
\text { momentos de alegria e tristeza, euforia e depressão, em um espaço curto de tempo. Conside- } \\
\text { rados os relatos que destacavam a expressão "oscilação emocional" como queixa principal. }\end{array}$ \\
\hline Pânico e medos & $\begin{array}{l}\text { Queixas de angústia diversas e difusas, medos que não têm uma causa identificada, medo } \\
\text { de sair de casa, de estar em multidões, entre outros, são alguns exemplos. Foram conside- } \\
\text { rados os relatos que apresentavam as palavras "medo" e/ou "pânico" nas triagens. }\end{array}$ \\
\hline Pressão social & $\begin{array}{l}\text { Queixas de se sentir pressionado pelas outras pessoas, sejam familiares ou colegas de } \\
\text { trabalho, referente a diferentes esferas da vida. Mais comum queixas de sentimentos de } \\
\text { pressão para conseguir um emprego, ou ser mais bem colocado no campo profissional. } \\
\text { Foram considerados os relatos que traziam as palavras "pressão social" nas triagens. }\end{array}$ \\
\hline Problema com a autoimagem & $\begin{array}{l}\text { Queixas referidas ao corpo, a própria imagem pessoal não satisfatória, aliadas em geral } \\
\text { a baixaestima. Foram consideradas as triagens que traziam a expressão "problemas com } \\
\text { autoimagem" em seus relatos. }\end{array}$ \\
\hline $\begin{array}{l}\text { Problema de atenção/ dificuldade de } \\
\text { aprendizagem }\end{array}$ & $\begin{array}{l}\text { Queixas que referiam dificuldades de aprendizado ou falta de atenção, detectados em casa ou } \\
\text { escola. Mais atribuídos às crianças, mas também adultos com dificuldade de concentração no } \\
\text { trabalho ou de desenvolver alguma atividade. Foram consideradas as triagens que traziam as } \\
\text { expressões "dificuldade de aprendizagem" e/ou "problemas de atenção" em seus relatos. }\end{array}$ \\
\hline Problema neurológico & $\begin{array}{l}\text { Relatos de triagens que traziam como principal motivo de procura do serviço de psico- } \\
\text { terapia o fato de ter sido diagnosticado algum problema neurológico, sendo este atendi- } \\
\text { mento parte do tratamento recomendado. Foram consideradas as triagens que traziam as } \\
\text { palavras "problema neurológico" em seus relatos. }\end{array}$ \\
\hline Problemas físicos/dor & $\begin{array}{l}\text { Queixas de sensações de dor ou qualquer outro problema físico que compromete, de } \\
\text { alguma forma, sua qualidade de vida, fazendo com que procurasse por psicoterapia. Foram } \\
\text { consideradas as triagens que possuíam as palavras "problemas físicos" e/ou "dor" como } \\
\text { principal causa de sua demanda pelo serviço. }\end{array}$ \\
\hline Problemas psíquicos/crise nervosa & $\begin{array}{l}\text { Queixas de acometimento de algum problema psíquico, já diagnosticado ou não, e/ ou } \\
\text { crises de ansiedade, expressas como "crises nervosas". Foram consideradas as triagens que } \\
\text { traziam essas expressões como principal causa da procura por psicoterapia. }\end{array}$ \\
\hline Psicossomática & $\begin{array}{l}\text { Queixas de sintomas físicos decorrentes de problemas sociais e/ou psicológicos, já identi- } \\
\text { ficados. Sensações de dor física, problemas dermatológicos, cardíacos, entre outros, cujas } \\
\text { causas são identificadas pelas pessoas como sendo de ordem psicológica ou social, como, } \\
\text { por exemplo, problemas com a família, moradia, trabalho, enfim, preocupações diversas. } \\
\text { Foram consideradas as triagens que traziam a expressão "psicossomática" em seus relatos. }\end{array}$ \\
\hline Sofreu agressão & $\begin{array}{l}\text { Queixas de agressões físicas, psicológicas e abusos sexuais sofridos. Foram considerados os } \\
\text { relatos que traziam essas expressões como principal motivo da demanda por psicoterapia. }\end{array}$ \\
\hline TOC/compulsão & $\begin{array}{l}\text { Queixas de compulsão por algumas coisas, como comprar, guardar, por limpeza, entre } \\
\text { outros, ou com Transtorno Obsessivo Compulsivo já diagnosticado. Foram consideradas as } \\
\text { triagens que traziam essas expressões como principal queixa em seus relatos. }\end{array}$ \\
\hline Outras & $\begin{array}{l}\text { Todas as demais queixas que não puderam ser classificadas nas categorias anteriores. } \\
\text { Demandas diversas, com frequência muito pequena em relação às demais, com apenas um } \\
\text { ou dois casos verificados, não tendo valor estatístico para esta investigação. }\end{array}$ \\
\hline
\end{tabular}

A partir dessa primeira análise verificamos que das 327 triagens investigadas, 158 eram mulheres, 76 eram homens e 93 eram crianças. A principal demanda na totalidade dos casos registrados e coletados, refere-se à dificuldade de se relacionar com os outros (com 49 queixas), seguida por depressão (com 30 queixas), pânicos e medos (com 21 queixas) e ansiedade (com 12 queixas), considerando o período analisado (ver Gráfico 1). 


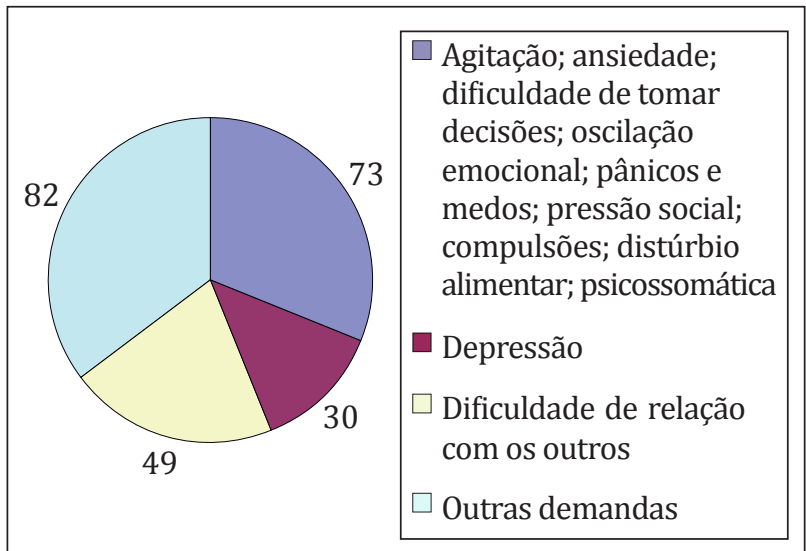

Gráfico 1 - Número de demandas comparadaas ao total de queixas Fonte: Dados da pesquisa.

Tanto para homens quanto para mulheres, a principal demanda foi em relação à dificuldade de se relacionar com os outros, com 18 e 31 queixas respectivamente, seguidas também por depressão, pânico e medo. No entanto, algumas categorias de queixas, apesar de pouco representativas quando comparadas às citadas anteriormente, apresentaram maior incidência em homens e outras categorias apresentaram maior incidência em mulheres. Predominantemente femininas foram as seguintes categorias de queixas: ciúmes, dedicação aos outros, oscilação emocional, luto, distúrbios alimentares, psicossomática e compulsão; enquanto que as queixas de agressividade e pressão social, foram predominantemente masculinas. 0 Gráfico 2 indica visualmente esses dados.

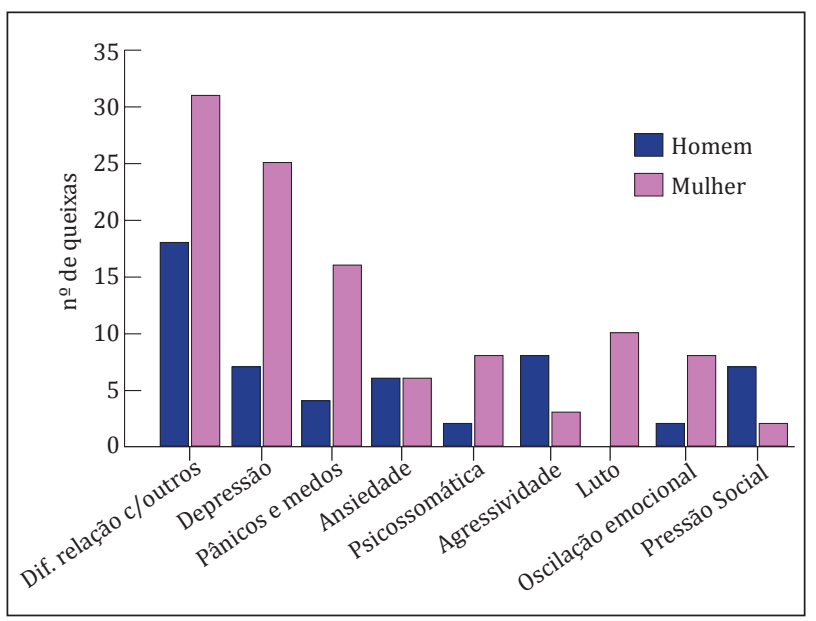

Gráfico 2 - Principais queixas de homens e mulheres Fonte: Dados da pesquisa.
A idade dos clientes também foi registrada e separada em faixas etárias. Considerando as diferentes faixas etárias, observou-se que o maior número de demandas por atendimento psicológico foi de crianças, com 93 clientes, na faixa de 0-13 anos. Dentre os adolescentes e adultos, o maior número de demandas surgiu na faixa de 21-30 anos (com 70 clientes).

\section{Cenário contemporâneo e sofrimento psíquico: Uma breve discussão}

Esses dados não nos surpreenderam completamente. Nossas discussões e leituras apontavam, em certa medida, para esta direção já que as bibliografias por nós exploradas seguiam um indício sobre a relação entre sofrimento psíquico e modo de vida na contemporaneidade. Percebe-se que parte significativa das queixas sofre interferência do cenário contemporâneo, sendo alimentadas pelas inquietações que alguns autores chamam de pós-modernas (Bauman, 1998). 0 mundo social que nos rodeia e no qual estamos completamente imersos, é também gerador de sofrimento psíquico e entendemos as inquietações e crises da atualidade (crise de identidade, crise de sentido, crise no trabalho, etc.) como problemas que têm uma relação bastante próxima com o sentido de urgência, consumo, estresse gerados pelo estilo de vida atual.

Dependendo do olhar que atribuímos a essa realidade, a visão de homem a partir da qual refletimos criticamente sobre a vida cotidiana e suas inquietações, pode privilegiar a liberdade e a diversidade dos modos de existir ou não. Nas ponderações de Karl Scheibe (1981), psicólogo e docente na Wesleyan University, nos Estados Unidos, há uma diferença fundamental entre um homem considerado como objeto científico e o mesmo homem encarado como um ator num palco histórico. A diferença, entretanto, não está no homem, está na atitude do observador. Considerando a premissa de que as ciências são supostamente atemporais, enquanto que a história social é evidentemente imersa em um contexto temporal, abre-se um polêmico campo de discussão a respeito da forma como se pode conduzir os estudos realizados pela ciência do comportamento, que para uns pode fazer parte tanto da ciência natural biológica quanto da ciência social.

Ao partirmos do ponto de vista que encara o homem como alguém que se faz no mundo em que 
vive e nas circunstâncias em que está inserido, descrever estas circunstâncias sociais passa a ser fundamental para se chegar o mais próximo possível do lugar onde esse homem se encontra. Esse procedimento desvela, em meio a tantos outros elementos, o sofrimento psíquico e a queixa clínica a partir de uma realidade cotidiana, sem ficar preso exclusivamente a entidades nosológicas universais que, muitas vezes, pode tratar as demandas como representações abstratas separadas do mundo e do tempo vivido. Apostando que os conhecimentos e sentidos construídos historicamente no agir social também fazem parte da experiência dos indivíduos, privilegiamos aqui o caráter social contido nas ciências do comportamento. Como tínhamos já o ponto de partida de que o homem não se faz fora de um mundo e de um contexto, entender as particularidades desse mundo passou a ser condição necessária para um entendimento mais completo da queixa clínica.

\section{Liberdade, indivíduo e eficiência técnica: A construção das subjetividades contemporâneas}

Acreditando não ser possível compreender as formações da subjetividade de maneira descolada das formações sociais nas quais estas se constituem, descrever o cenário fundador do homem contemporâneo passa a ser fundamental. Dessa maneira, na tentativa de desvelar esse homem e ir até onde ele se encontra, tomaremos aqui como ponto de partida o contexto atual conhecido por alguns autores como hipermodernidade (Lipovetsky, 2004), época caracterizada por uma intensificação de tudo o que envolve a vida moderna, uma exacerbação e aceleração da vida, na qual a oferta de uma liberdade individual, iniciada com a modernidade, torna-se definitivamente soberana. 0 mundo hipermoderno, para Lipovetsky (2004), é caracterizado pela liberdade, movimento, flexibilidade e valorização do bom desempenho, fincando seus alicerces no mercado, na eficiência técnica e na promoção da noção de indivíduo.

Podemos observar que diante de um mundo hierarquizado e de tradições sociais bem definidas, o advento da modernidade e de suas ideias de Liberdade e Igualdade provocaram um corte na maneira de pensar o homem e a realidade. Assim, é com o pensamento iluminista do século XVIII que vemos a consolidação das experiências subjetivas individualizadas, assim como a consolidação da capacidade humana de domínio de si e da natureza.

Luís Cláudio Figueiredo (1996) acentua que tal período conhecido como modernidade fez surgir uma nova posição de homem, onde cada vez mais entregue a si, o indivíduo defronta-se com um mundo no qual "já não se sente em casa e de onde lhe surgem fenômenos dotados de certa estranheza que exigem o máximo empenho em procedimentos de controle" (Figueiredo, 1996, p. 16). Assim, passamos a observar um crescente processo de matematização da vida e de busca por previsibilidades, dando origem a um sujeito moderno que passa a se impor uma autodisciplina, buscando assim controlar tudo aquilo que fosse irregular e imprevisível de sua experiência subjetiva.

Logo, é a exacerbação dessa liberdade individual que novamente ganha espaço neste novo cenário, como o maior predicado desse sujeito contemporâneo conhecido também como sujeito hipermoderno. É possível perceber, neste contexto, o quadro de sofrimento psíquico que investigamos e no qual o problema da intersubjetividade aparece como problema primordial. É perfeitamente compreensível, em vista desse quadro, que nossa época seria, na visão de Bauman (2001), uma versão individualizada e privatizada da modernidade, na qual a responsabilidade sobre o fracasso ou sobre a vitória recai quase que exclusivamente sobre os próprios indivíduos, o que pode ajudar a compreender o aumento da sensação de estresse e pressão permanentes constatadas em nossas investigações.

Em nenhum outro contexto histórico o sedutor slogan "Querer é poder" vendeu tantos produtos e conquistou tantos adeptos. Tudo passa a depender da vontade e da determinação do indivíduo. Aquele que "não progride" é mal visto socialmente, assim como se associa silêncio à tristeza ou depressão. Não progredir atualmente pode significar que socialmente está paralisado pelos seus sentimentos de inferioridade ou pela sua inadequação às demandas do mundo, o que nos ajuda também a compreender o maior número de pessoas deprimidas e com a sensação de não saber lidar com os outros, desenvolvendo sentimentos mesmo de inadequação ao contexto que vive. Assim, estaríamos diante de um indivíduo livre e ao mesmo tempo sedento pela eficácia técnica, pelo imediatismo, pela fluidez e pelo excesso. 
Associada a esses pilares formadores da noção de um homem livre, vem a exacerbação da ideia moderna de soberania do indivíduo consumidor (Slater, 2002). Como os consumidores são autônomos e soberanos em suas necessidades e desejos, eles podem ser o que quiserem, desde que a realização do desejo já esteja disponível no mercado. Surge aí uma espécie de liberdade paradoxal, já que ela aparece quase sempre condicionada ao consumo de algum produto, seja o consumo de uma ideia, de um elixir para a juventude ou até mesmo de uma pílula para resgatar a tal felicidade perdida.

Não seria ousado afirmar que estamos, na verdade, diante de um indivíduo preso em sua suposta liberdade, posto que, diante de tantas possibilidades, sente-se confuso e perdido, acabando por orientar suas escolhas de acordo com as demandas sociais de sucesso e status (Bruckner, 2002). Tal fato pode ser observado nas queixas encontradas em nossa investigação, referente a sentimentos de pressão social, relatadas primordialmente por homens, e nas queixas de dificuldade de tomar decisões, podendo ser constatado também no cotidiano. Isso quando observamos escolhas profissionais, amorosas, entre outras, guiadas por ideais e produtos de sucesso e felicidade, amplamente divulgados nos meios de comunicação e pela propaganda, demonstrando assim que a liberdade é exatamente o fato de poder comprar tais produtos e ideais. Está aí, portanto, o paradoxo da liberdade moderna, já que esta é condicionada e direcionada ao consumo.

Assim, um consumidor passa ser um herói não quando está simplesmente comprando, mas sim quando essa iniciativa é vista como um aspecto de um conceito mais amplo de homem moderno: um homem autônomo, que procura satisfazer racional, livre e vigorosamente seus próprios interesses e vontades.

Com o primado conferido à individualidade do homem, este se torna cada vez mais o centro dos valores e do conhecimento. Japiassu (1975) ressalta que é por meio de uma leitura antropocêntrica que a verdade aparece como uma obra humana, cujas estruturas devem ser examinadas em sua referência ao homem que é ao mesmo tempo seu inventor e seu suporte. Inicia-se assim a descoberta, iniciada por Descartes com o Cogito, do sujeito cognoscente autônomo.

Ao ousar duvidar do conhecimento ditado pelo mundo hierarquizado da idade média e ao romper com toda tradição escolástica medieval, Descartes em seu Discurso do método (2007), ainda no século XVII idealiza um método, o analítico, com a intenção de construir uma ciência da natureza pautada na certeza, traz mudanças que permeiam a percepção do sofrimento psíquico até os dias de hoje.

Assim, outro fator fundamental na formação desse ideal de subjetividades autônomas, que não pode deixar de ser citado, é a consolidação do modelo de racionalidade proveniente da ciência moderna introduzido por Descartes. Ao explicar a existência humana como sendo uma consequência direta da razão com a célebre tese de que penso, logo existo, o método cartesiano sugere uma centralização na figura emblemática da razão e acompanhando-a, naturalmente, a dicotomia entre mente-corpo, sujeito-objeto. Surge a partir daí o olhar da racionalidade pautada no culto à fragmentação: a ideia de dividir para melhor controlar passa a fazer parte da vida cotidiana influenciando inclusive o modo como os sujeitos percebem sua própria existência.

Assim, homens passam cada vez mais buscar a solução mais imediata e objetiva para seus desvios individuais, sem se importarem com quaisquer práticas ou responsabilidades sociais possivelmente inseridas em tal cenário. Portanto, essa característica contemporânea de fragmentação da realidade e de dicotomia corpo-mente pode ser entendida como mais um efeito do culto ao individualismo que o Liberalismo moderno coloca em cena. A ciência contemporânea, influenciada por esses preceitos, tende a explicar os sentimentos, emoções e comportamentos a partir da biofisiologia humana, não considerando os aspectos sócio-culturais aí embutidos. Como consequência, se o indivíduo está muito distraído, deprimido ou até mesmo com ataques de pânico, a responsabilidade por tal estado é atribuída quase que exclusivamente a uma produção inadequada de neurotransmissores ou a algum outro desvio neurobiológico.

Os especialistas passam então a assumir cada vez mais um olhar onipotente e fragmentado sobre a vida e sobre o mundo, aumentando a sensação de impotência e de vitimização do homem contemporâneo, que diante de tantos meios de coerção, acaba acreditando que não é capaz de lidar sozinho com seus desconfortos existenciais, necessitando impreterivelmente recorrer às soluções mágicas que a razão técnico-científica pode lhe proporcionar. É nesse contexto que ganha espaço o fenômeno da 
medicalização da vida tão facilmente observado nos dias de hoje. Um sofrimento passa então a ser tratado unicamente como um fator isolado dentro da máquina biológica humana, tendo seu contexto histórico-social quase sempre retirado de cena.

Vemo-nos imersos, portanto, em uma eficiente engrenagem produtora de modos de subjetivação, na qual prevalecem certas relações de poder-saber produtoras de necessidades, diagnósticos, doenças, teorias e especialistas. Dessa forma, seria possível afirmarmos que o homem contemporâneo vive de fato a dificuldade de escolher o seu modo próprio de viver: Distúrbio de explosão intermitente, Transtorno de deficiência motivacional, Transtorno desafiador opositivo, Síndrome das pernas inquietas, Depressão e seus leques variados de opções, Transtornos de Hiperatividade... São tantas as possibilidades, que o ato de se diagnosticar com algum transtorno e de agir conforme objeto paciente de tal categoria, passou a pertencer ao campo da banalidade e paradoxalmente, ao da normalidade.

A técnica passa então a ser usada como um instrumento que oferece todo um arsenal de recursos pensáveis e impensáveis para uma maior produtividade e para a extinção de qualquer sofrimento, restringindo o homem ao sentido único de recurso, de produto a ser explorado. Tudo passa a ter um para quê a priori geralmente vinculado a um possível lucro ou vantagem. $O$ contato com o mundo passa a ser cada vez mais funcional, pragmático. Como nos aponta o filósofo Emmanuel Carneiro Leão (1975), a lógica do cálculo passa a cada vez mais invadir nossas relações com o mundo em detrimento da lógica do sentido.

Assim, segundo Lipovetsky (2007), a imagem prevalente desses tempos hipermodernos seria a sociedade do desempenho, na qual todos são intimados a ser superativos e operacionais em todas as coisas. 0 modelo de desempenho é assim convocado de uma maneira banalizada, havendo um excesso de assédio pelas normas técnicas e uma corrida generalizada pela excelência.

Um dos grandes problemas aí envolvidos é que essa restrição de sentido e de possibilidades tem sido tão atroz que, em muitos dos casos, se o homem não atinge a esse modelo imposto como sendo o ideal, ele acaba deprimindo e sentindo os duros efeitos de ser tomado como mais um arquivo danificado dentro de uma engrenagem social movida por regras rígidas de modos de se comportar no mundo.

\section{A busca pela felicidade utópica}

Num capitalismo baseado no consumo, a felicidade se torna também um produto a ser consumido. Os indivíduos contemporâneos sedentos por felicidade passam a consumir compulsivamente imagens midiáticas e produtos utopicamente embutidos de signos relacionados a determinados estilos de vida que prometem trazer a tal felicidade.

De acordo com Bruckner (2002), a partir da segunda metade do século XX a felicidade foi tomada como um dever; já que transformada em dogma que passa a intimar à euforia e atirar no mal-estar os que não conseguem atingi-la. A felicidade pode então ser considerada, segundo este autor, como a forma pela qual cada contexto sócio-histórico considerou o que era desejável e decidiu a respeito do que seria considerado prazeroso ou desagradável. Assim, os homens e mulheres contemporâneos sentem-se sentenciados à busca da felicidade a qualquer custo. Ser feliz passou a ser um dever moral do homem contemporâneo.

De forma a ajudar a cumprir esse dever, pautados na eficiência técnica e influenciados pela valorização social do desempenho, muitos produtos e serviços são colocados à disposição do homem hipermoderno, desde remédios e drogas estimulantes até aconselhamentos e livros de autoajuda, que fornecem maneiras de se alcançar a felicidade almejada. Esses produtos ensinam os indivíduos a atingir seus máximos em termos de desempenho e felicidade nos relacionamentos, no trabalho e nas relações pessoais, na criação dos filhos e na forma de lidar com a alteridade de maneira geral. A psicoterapia faz parte também do rol desses serviços que podem ser comprados para ajudar o indivíduo hipermoderno à melhor satisfazer suas necessidades, como um remédio que pode ajudá-lo a encontrar seu lugar nesse mundo.

Além disso, pode-se observar que a ideia contemporânea de que cada um é responsável pelo seu destino e, portanto, responsável pelo seu sucesso ou fracasso, uniu os ideais de liberdade e felicidade, devendo-se exercitar a primeira de forma a alcançar a segunda. Como cada homem e mulher contemporâneos têm que assumir a responsabilidade por sua vida e pelo sucesso tão amplamente desejado, acabam experienciando também uma forte angústia diante do poder que têm nas mãos. Aí está o paradoxo de que nos fala Bruckner (2002), no qual, 
apesar de livre, o homem muitas vezes permanece imobilizado diante de tantas possibilidades e, principalmente, diante da angústia gerada pela responsabilidade de ser feliz.

Tal concepção contemporânea de felicidade poderia então estar não apenas intimamente relacionada com o alto número de diagnósticos de depressão e estresse encontrados em nossa investigação, como relacionado ao quadro geral de queixas direcionadas ao serviço. Assim, quem não consegue atender a tais imperativos da atualidade imediatamente é incorporado a alguma categoria nosológica, sendo esta mais uma possível maneira do homem contemporâneo negar sua liberdade e responsabilidade diante da angústia proveniente do paradoxo e ambivalência em que vive. Como não há tempo nem espaço para se defrontar com a angústia, o homem acaba adotando para si comportamentos defensivos, que em muitos dos casos são as próprias demandas que chegam ao serviço de Psicologia, em formato de medos e ansiedades excessivas, depressões, fobias, entre outras queixas.

Se uma pessoa, em algum instante, desvia da engrenagem idealizada, é colocada imediatamente para conserto e provavelmente será alvo de muitos tratamentos que lhe tragam de volta à normalidade. Diante disso, pode-se inclusive afirmar que tal lógica de exclusão não é muito diferente do tratamento moral introduzida por Pinel na virada do século XVIII para o XIX, sendo, porém, a lógica atual muito mais sutil e sofisticada graças aos avanços da técnica. A recuperação anteriormente proposta pelos alienistas, detentores máximos da verdade, hoje é sugerida por uma série de especialistas $p s i$, que vão tentar justamente consertar aqueles que de alguma forma não se adequam às exigências contemporâneas. Assim, os técnicos "psi" ultrapassam os muros do asilo e se alastram por todo tecido social, ajudando na consolidação da utopia moderna de classificação e encarceramento do homem moderno.

Diante da exacerbação das questões modernas, passamos também a observar um crescente processo de busca por controle e previsibilidades. Tal processo ajuda a aumentar a dificuldade em tolerar os riscos, frustrações e desconfortos existentes no relacionar-se com o outro. Aquilo que ameaça as certezas do homem contemporâneo e quebra a utopia de uma felicidade completa e diária deve ser imediatamente retirado de cena.
Para que se expor para o outro e estabelecer relações afetivas, se a permanência nos lugares é efêmera e fluida? Fica mais fácil então se voltar para um núcleo interior, que Lasch (1984) chama de um mínimo eu e dialogar com o resto do mundo a partir desse núcleo fechado. Nessa busca frenética por certezas, o eu torna-se absoluto e fonte de decisão, contribuindo para que questões íntimas sejam cada vez mais privilegiadas em detrimento de questões públicas e sociais; dado que nos ajuda novamente a pensar a queixa de dificuldade de relacionar-se com o outro, constatada em maior número nas triagens investigadas.

Assim, pode-se observar que os ideais de liberdade e felicidade amplamente disseminados e valorizados pela sociedade contemporânea acabam funcionando como agentes promotores de medo e angústia, levando os indivíduos a se esforçarem desesperadamente por manter bons níveis de desempenhos e adquirir o conhecimento das técnicas, utilizadas como ferramentas capazes de promover a tal liberdade e felicidade. Todavia, a busca desesperada por esses imperativos hipermodernos tem provocado uma insatisfação e embotamento constantes, retratados amplamente nas triagens investigadas por nós.

\section{Considerações finais}

Diante dos elementos aqui expostos, pode-se perceber que nossa subjetividade é diretamente afetada, senão forjada, pelos ideais modernos de liberdade individual, felicidade e desempenho, intensificados na hipermodernidade.

Estes chamados tempos hipermodernos que nos rodeiam poderiam ser caracterizados então por grandes paradoxos. De um lado, a sociedade não para de instigar os gozos do consumo, do imediatismo e da fluidez, intensificados pelos avanços tecnológicos e a consequente compressão espaço-temporal, que permitem e exigem que tudo aconteça no aqui e agora, corroborando ainda mais para uma fragmentação e flexibilização nos novos modos de ser (Bauman, 2001). De outro lado, a vida passa a exigir mais eficácia técnica e desempenho, tornando-se consequentemente mais estressante. A hipermodernidade passa então a ser caracterizada por um composto paradoxal de frivolidade e ansiedade, de euforia e vulnerabilidade. 
0 culto pela velocidade e pela vivência intensa do presente tem pertencido ao cotidiano de um número cada vez maior de pessoas. A primazia do presente se instalou associado à busca pelo excesso. Para Lipovetsky (2004), uma das consequências mais visíveis dos tempos hipermodernos que nos regem hoje é o clima de pressão que ele faz pesar sobre a vida das pessoas. Um ritmo frenético, um agir sem demora e a corrida da competição fazem priorizar o urgente à custa do importante, a ação imediata à custa da reflexão, além de ajudar a criar uma atmosfera de dramatização, de estresse permanente. Tal como sugerem autores como Berger e Luckmann (2004), aliado à fragmentação, ao individualismo, ao aumento da velocidade das trocas (de informação e pessoas), e à descartabilidade das nossas ações e experiências, há o sentimento de liberdade que pode gerar sentimentos de indecisão e de perda de parâmetros, levando a um grande sofrimento subjetivo, conforme foi corroborado na investigação realizada.

A insegurança e a incerteza vêm ocupando espaço nas diferentes esferas da vida e o homem contemporâneo passa a refletir em seu modo-de-viver-no-mundo o paradoxo em que se encontra esse mesmo mundo. Como conviver com um tempo que nunca dá tempo?: eis um eco fácil de ressoar nas mais variadas esquinas cotidianas.

Assim, fica cada vez mais claro como a técnica e sua exacerbação pela busca por controle, certeza e previsibilidade tem entrado em choque com a insegurança, fluidez e descartabilidade próprias dos dias de hoje, trazendo à tona nossa condição de abertura, de vulnerabilidade. Não suportando conviver com o desconforto existente nessa condição de desamparo, nos deparamos com um aumento cada vez maior de tentativas de resolução dos paradoxos que nos rodeiam, o que aponta para uma dificuldade bem típica do mundo que nos constitui, que é a dificuldade de se reconhecer como um ser lançado no mundo, vulnerável, exposto à fragilidade, ao sofrimento, à frustração, à velhice e por que não à morte, um dos grandes tabus dos dias de hoje. E é tentando lutar contra esses paradoxos e controlar o incontrolável que o homem contemporâneo cada vez mais restringe o sentido de seu existir a comportamentos fóbicos e ansiosos, por exemplo.

Portanto, talvez não seja ousado pensar que as demandas apresentadas nos Serviços de Psicologia representam, na verdade, sentimentos e comportamentos humanos de resistência e defesa contra a insegurança e angústia geradas, dentre outras coisas, pelo ritmo frenético das trocas, pelo individualismo extremo e a consequente autorresponsabilização dos atos (de sucesso ou fracasso), bem como pelos utópicos ideais de liberdade e felicidade. Mas que acabam sendo interpretadas na hipermodernidade, não como reação subjetiva ao contexto histórico-cultural, mas sim enquanto manifestação patológica demonstrativa de fraqueza e fracasso.

As queixas observadas nas triagens realizadas no Serviço de Psicologia da UERJ nos indicam uma relação com o contexto sócio-histórico no qual estão inseridas e, por mais idiossincrasias que possam apresentar, graças às experiências e vivências biopsicossociais de cada um ao longo da vida, revelam que a atual conjuntura é propensa a gerar sentimentos de solidão e de fracasso, bem como experiências de vazio de sentido, mostrando uma estreita relação entre a angústia que constitui as ambivalências contemporâneas e as demandas observadas no Serviço de psicologia pesquisado. Todavia, é necessário ressaltar a importância de realizarmos mais pesquisas e estudos nessa área para podermos ter acesso a dados e reflexões que deem cada vez mais consistência às relações aqui discutidas entre modos de vida e demandas psicoterápicas. Sem qualquer pretensão de estabelecer uma relação de causa e efeito, senão apenas tentar chegar a uma compreensão mais real e autêntica de tais demandas, é necessário chamar atenção para o fato de que talvez seja o mais importante objetivo desse estudo: a necessidade de se considerar que múltiplos e diferentes fatores contribuem para constituição de uma subjetividade sadia ou não, bem como para a formulação de uma queixa, que, por sua vez, pode ou não chegar a um serviço de psicologia.

Como podemos notar, essas reflexões nos apontam para a importância de entender a demanda psicoterapêutica dentro da relação do sujeito com o mundo e nunca como uma entidade universal e fragmentada do mundo em que se vive. Assim, compreendendo a realidade existencial do homem como sendo também a forma como ele se relaciona com o contexto e com o mundo que o cerca, acreditamos ter conseguido reiterar aqui que a prática clínica necessita deixar de pertencer a uma experiência puramente do âmbito íntimo, passando a pertencer também a um âmbito histórico-político-social. 


\section{Referências}

Bauman, Z. (1998). O mal-estar na Pós-Modernidade. Rio de Janeiro: J. Zahar.

Bauman, Z. (2001). Modernidade líquida. Rio de Janeiro: J. Zahar.

Berger, P. L., \& Luckmann, T. (2004). Modernidade, pluralismo e crise de sentido. Petrópolis: Vozes.

Bruckner, P. (2002). A euforia perpétua: Ensaios sobre o dever de felicidade. Rio de Janeiro: Difel.

Dercartes, R. Discurso do método. São Paulo: Martin Claret, 2007.

Figueiredo, L. C. (1996). Revisitando as psicologias: Da epistemologia à ética das práticas e discursos psicológicos. Petrópolis: Vozes.
Japiassu, H. (1975). Introdução à epistemologia da psicologia. Rio de Janeiro: Imago

Lach, C. (1984). 0 mínimo eu: Sobrevivência psíquica em tempos difíceis. São Paulo: Brasiliense.

Leão, C. E., \& Lacombe, P. F. (1975). Existência e psicanálise. Rio de Janeiro: Tempo Brasileiro.

Lipovetsky, G. (2004). Os tempos hipermodernos. São Paulo: Barcarolla.

Lipovetsky, G. (2007). A felicidade paradoxal: Ensaio sobre a sociedade de hiperconsumo. São Paulo: Companhia das Letras.

Scheibe, K. E. (1981). Espelhos, máscaras, mentiras e segredos. Rio de Janeiro: Interamericano.

Slater, D. (2002). Cultura do consumo e modernidade. São Paulo: Nobel. 
